Developing Global Leaders for Research, Regulation and Stewardship of Crop Protection Chemistry in the $21^{\text {st }}$ Century

John B. Unsworth* ${ }^{1}$, Camilla Corsi ${ }^{2}$, Jeanette M. Van Emon ${ }^{3}$, Annemieke Farenhorst ${ }^{4}$, Denis J. Hamilton ${ }^{5}$, Cody J. Howard ${ }^{6}$, Robert Hunter ${ }^{7}$, Jeffrey J. Jenkins ${ }^{8}$, Gijs A. Kleter ${ }^{9}$, Rai S. Kookana $^{10}$, Joseph O. Lalah ${ }^{11}$, Michael Leggett ${ }^{12}$, Karina S. B. Miglioranza ${ }^{13}$, Hisashi Miyagawa $^{14}$, Natalia Peranginangin ${ }^{15}$, Baruch Rubin ${ }^{16}$, Bipul Saha ${ }^{17}$, Najam A. Shakil ${ }^{18}$

${ }^{1}$ Independent Consultant, Chelmsford, CM1 7EA, UK

${ }^{2}$ Syngenta Crop Protection, WST-810.3.38, Schaffhauserstrasse, CH-4332 Stein, Switzerland

${ }^{3}$ Human Exposure \& Atmospheric Sciences Division, National Exposure Research Laboratory, US EPA Office of Research and Development, 944 East Harmon Avenue, Las Vegas, NV 89119, USA

${ }^{4}$ Department of Soil Science, Faculty of Agricultural and Food Sciences, University of Manitoba, 380 Ellis Building, Winnipeg, Manitoba R3T 2N2,

Canada

${ }^{5}$ Formerly Queensland Department of Primary Industries, Taringa, Queensland 4068, Australia

${ }^{6}$ California Air Resources Board, P.O. Box 2815, Sacramento, CA 95812, USA

${ }^{7}$ CropLife International, 326 Avenue Louise, Box 35, 1050 Brussels, Belgium

${ }^{8}$ Department of Environmental and Molecular Toxicology, 1007 Ag \& Life Sciences, Oregon State University, Corvallis, OR 97331-7301, USA

${ }^{9}$ RIKILT Wageningen UR, P.O. Box 230, 6700 AE Wageningen, The Netherlands 
${ }^{10}$ Environmental Contaminant Mitigation and Technologies, CSIRO, Land and Water

National Research Flagship CSIRO, Waite Campus, PMB 2, Glen Osmond 5064, Australia

${ }^{11}$ Department of Chemical Science and Technology, Technical University of Kenya, Haile Selassie Avenue,P.O. Box 52428-00200, City Square, Nairobi, Kenya

${ }^{12}$ CropLife America, 1156 15th Street N.W., Suite 400, Washington, DC 20005, USA

${ }^{13}$ Laboratorio de Ecotoxicología y Contaminación Ambiental, Instituto de Investigaciones Marinas y Costeras-CONICET FCEyN, Universidad Nacional de Mar del Plata, Funes 3350 (7600) Mar del Plata, Argentina

${ }^{14}$ Division of Applied Life Sciences, Graduate School of Agriculture, Kyoto University, Kyoto 606-8502, Japan

${ }^{15}$ Syngenta Crop Protection, LLC., P.O. Box 18300, Greensboro, NC 27419-8300, USA

${ }^{16}$ RH Smith Institute of Plant Science and Genetics in Agriculture, Faculty of Agriculture, Food and Environment, The Hebrew University of Jerusalem, Rehovot 76100, Israel

${ }^{17}$ Nagarjuna Agrichem Limited, Hyderabad - 500 082, India

${ }^{18}$ Division of Agricultural Chemicals, Indian Agricultural Research Institute (IARI), New Delhi - 110 012, India 
2 ABSTRACT: In order to provide sufficient food and fibre to the increasing global population

3 the technologies associated with crop protection are growing ever more sophisticated but, at

4 the same time, societal expectations for the safe use of crop protection chemistry tools, are

5 also increasing. The goal of this perspective is to highlight the key issues that face future

6 leaders in crop protection, based on presentations made during a symposium, entitled

7 "Developing Global Leaders for Research, Regulation and Stewardship of Crop Protection

8 Chemistry in the $21^{\text {st }}$ Century", held in conjunction with the IUPAC 13th International

9 Congress of Pesticide Chemistry in San Francisco, CA during August 2014. The

10 presentations highlighted the fact that leaders in crop protection must have a good basic

11 scientific training, understand new and evolving technologies, are aware of the needs of both

12 developed and developing countries and have good communication skills. Concern is

13 expressed over the apparent lack of resources to meet these needs and ideas are put forward

14 to remedy these deficiencies.

15 KEY WORDS: crop protection, stewardship, sustainable agriculture, women in agriculture,

16 smart systems, nano-pesticides, GM crops, training leaders, communications, developing

17 regions, universities 
INTRODUCTION

In the future, as the global population increases, it will be essential to produce more food from a decreasing arable land area. Crop protection chemistry leaders can play an important role in this but they will face several key challenges and will need to be able to integrate results from research spanning agriculture, food, water, health, energy and the environment. At the same time, they should be able to take into account new and evolving technologies and how any changes to current practices would be perceived by the general public. Key areas for future leaders include sustainable agriculture, the role of women in agriculture, new and developing technologies, communications, developing regions, training needs and changes in regulations. Variously experienced career professionals in industry, academia, and government from developing and developed economies gave presentations on these topics, followed by discussion break-out sessions, in a symposium held in conjunction with the IUPAC 13th International Congress of Pesticide Chemistry in San Francisco, CA during August 2014. The objective of the symposium was to develop specific recommendations for ensuring that future leaders and innovators in crop protection technology are broadly trained, have a global perspective, and rely on the best available science.

\section{SUSTAINABLE AGRICULTURE}

This is an issue which cannot be ignored for leaders in crop protection and this topic was addressed by K. S. B. Miglioranza in her presentation - "Sustainable agriculture: Where are we going? Stewardship and Sustainability for Crop Protection Practices". Since 1960 there has been a significant increase in food production and although the population has doubled since then there has been a dramatic decrease in the proportion of the population going hungry. However, over this period land cultivated for food production has been lost due to urbanization, desertification, salinization, soil erosion, and other consequences of unsustainable land management. This trend is likely to be exacerbated by climate change and 
the growing of biofuels.(1) The worldwide population is still increasing and global food production must rise by $70 \%$ by 2050 to meet the demands of this increase in population and about $80 \%$ of this increased production must come from existing arable land through higher yields. Given these trends, increasing food production will need crop improvement through breeding and increased inputs of fertilisers and pesticides, particularly in developing countries where nearly $90 \%$ of the increase in annual production will take place.(2) It is in these countries where the practices of sustainable agriculture are most important today, in developed countries these are already mostly in place. Sustainable agriculture enables the production of sufficient food without compromising the ability of future generations to do the same, this includes sustainable land management in order to maintain or enhance this vital resource. Sustainable agriculture can be considered to integrate three main goals environmental health, economic profitability, and social and economic equity.(3) In working with developing countries future crop protection leaders must make sure that the lessons of the past are not forgotten and, by good stewardship, ensure that farming techniques are used that protect the environment, public health, animal welfare and human communities. In addition, agricultural techniques and policies should offer innovative and economically viable opportunities for growers, labourers, consumers, policymakers and many others in the entire food system. This implies interdisciplinary efforts in research and education, involving not only crop protection leaders but also farmers, farm workers, consumers and policymakers in the developing countries.

\section{WOMEN IN AGRICULTURE}

Smallholder farmers produce more than half the global food supply from a small portion of the farmable land available. Women smallholders comprise an average of $43 \%$ of the agricultural labour force of developing countries with up to $79 \%$ in the least developed countries.(4) Structural changes now underway in world agriculture will necessitate that 
future agriculture leaders consider the important role of women in feeding an increasing population according to A. Farenhorst in her presentation "Agricultural Education, Research and Outreach: The Importance of Diversifying our Action". For smallholders men are typically the "public face" of family owned farms and have access to resources seldom available to women farmers - including land, financing and technology. For future progress it is important that the training of women farmers must address the specific constraints that they face. Empowerment requires women to be part of the decision-making process, including the development of new technologies, the communication and scientific awareness thereof, and transferring best practices through training, education and stewardship. Bringing yields on the land farmed by women up to the levels achieved by men would increase agricultural output in developing countries between $2.5 \%$ and $4 \%$.(5) The challenge for crop protection leaders is how to strengthen gender equality to ensure that women have the same access to education and training as their male counterparts and are able to participate equally in the decision making process.

\section{NEW TECHNOLOGY}

Technology is having a major impact on agriculture in developed countries and, in time, this will trickle down to economically and technologically developing regions. In her presentation "There is Nothing Permanent Except Change" N. Peranginangin looked at the new and upcoming technologies from the viewpoint of a young scientist in the agrochemical industry. Many of the upcoming technologies are based on the massive increase in computer power now available, linked with the potential for miniaturisation. Some examples are "smart systems" which can build up a database of information about each plant. This can be used to detect the onset of disease which can then be treated automatically, thus only those plants that require attention are sprayed instead of spraying an entire field. By observing the development of each plant, crop yields can be predicted more accurately. Automated 
harvesters can then use the database to identify and gather individual produce whenever it is ready for harvest.(6) Integrated field computers are also now used which give precision guidance, auto-steering, control of application rate, automatic boom control and wireless data transfer. Communication and data transfer systems are becoming more rapid and easier to use, more and more data are being produced to be examined and cross-examined, which requires "Big Data Analytics" to support better decision making.(7) Increases in computing power have allowed the development of web-based and more complex models, such as cloud-based environmental models for evaluating pesticide risks to ecosystems.(8) For the $21^{\text {st }}$ Century it is essential that the leaders have an understanding of the latest technologies, multi-disciplinary thinking and improved ways of working, as well as an ability to integrate opportunities, promote innovation and develop the right tools to make the right decisions. For all professionals training will be ongoing throughout their careers.

\section{DEVELOPING TECHNOLOGIES}

Technologies are constantly being developed and adopted by the farming community. As examples of these developing technologies presentations were made concerning nanotechnology and GM crops. Nano-pesticides or nano plant protection products represent an emerging technological development that, in relation to pesticide use, could offer a range of benefits including increased efficacy, durability, and a reduction in the amounts of active ingredients used, hence leading to reduced environmental exposure. However, it is essential that any risks associated with the use of nano-pesticides are understood and that relevant tests are included in the regulatory requirements. This topic was discussed in the presentation "Nanotechnology and Development of Plant Protection Products: Regulatory Considerations" of R. Kookana. Over the past few years the number of scientific publications, including patents, dealing with nano-materials and agriculture has increased exponentially.(9) Interestingly, there is currently no widely accepted definition of a nano- 
pesticide, although a working definition has been proposed thus: "a nano-pesticide is a pesticide product where nanotechnology, i.e. the use of materials that have a physical form with at least one dimension in the range $1-100 \mathrm{~nm}$, is employed to enhance the efficacy and/or reduce the environmental footprint of a pesticide active ingredient".(10) Engineered nano-particles (ENPs) are receiving increasing interest in the development of a range of plant protection products. However, there is an increasing body of evidence that the factors and processes affecting the environmental behaviour ENPs may differ from "conventional" substances and consequently, that methods used in current risk assessment approaches may need refining or replacing.(9) In order that scientists involved in this technology and also the public at large are convinced of the safety of nano-pesticides it is necessary to address aspects such as analysis and characterization, environmental fate assessment, and ecotoxicological risk assessment in aquatic and terrestrial ecosystems. The initial approach is to assess whether the presence of the nano-pesticide introduces potential differences compared to the conventional active ingredients. From this comparison any proposed changes in the test methodology could be used to facilitate the development of regulatory approaches for nanopesticides.

G. Kleter introduced the subject of genetically modified crops in his presentation - "New and Evolving Technologies: GMOs (Genetically Modified Organisms)". GM crops have been readily adopted in some countries e.g. the USA, Brazil and Argentina but not in other regions e.g. Europe. Nevertheless, since the introduction of GM crops in 1996 the area dedicated to them has increased year on year, and in 2013 a record 175.2 million hectares of GM crops were grown globally. With regard to the traits introduced into these crops, most are of potential benefit to the agricultural sector, particularly insect and herbicide resistance. Recent developments indicate that the GM crops to be introduced into the market in the near future will have a more diversified range of traits such as nutritionally improved crops with 
enhanced vitamins, polyunsaturated fatty acids, and other nutrients of interest, as well as crops with, non-food uses such as biofuel or pharmaceutical production. Similarly, crops created with new technologies at the borderline between conventional breeding and recombinant DNA technology are emerging, such as the introduction of genetic material from the same or closely related plant species (e.g. cisgenesis), and targeted mutations in host plant genes without the introduction of exogenous DNA (e.g., oligonucleotide-directed mutagenesis). While the safety assessment of these crops follows a rigorous, internationally harmonized approach, and the scientific consensus is that GM foods do not pose any risk, leaders have found themselves confronted with other arguments beyond safety in public debates, and there is significant hostility in some countries against GM crops. It must be recognised that there is a distinction between scientifically assessed risk and perceived risk, and the public's beliefs about risk may be very different from the beliefs of experts. Leaders in crop protection must acknowledge that perceived risk, even in the absence of any scientific evidence, can be a powerful force in the non-acceptance of new technologies. Such awareness of societal issues could be stimulated, for example, by inclusion of pertinent features of social sciences and humanities into the curricula of future leaders' education.

\section{COMMUNICATIONS}

Communications today are more rapid than they have ever been and this area was looked at by R. Hunter in his presentation "Living with Instant Communication". Every day we are bombarded with instant information - surfing the internet, exchanging emails and using our social media networks and with each piece of information we are challenged to make quick decisions. Managing communications in this environment requires a proactive strategy of preparedness, community building and understanding how to best deliver your message to your audience. For leaders in crop protection it is essential that they understand how negative campaigns are created and what can be done to reduce their impact. Of course, if there is any 
truth in the campaign this needs to be acknowledged in a transparent manner. It also should be noted that purely scientific arguments by experts may not be enough to convince the public who may not have sufficient understanding of the finer points e.g. in the debate on GM crops. This is not a new problem and was flagged up in R. Don Wauchope's paper in 2000 where he wrote that "It is the despair of scientists that the public is so very ignorant technically, but public fears, ignorant or not, have to be addressed, both because it is a democracy and because it is the humane thing to do".(11) New campaigns are generally focused, for example on bees not wildlife or children not the environment. Criticisms may be based on some sort of reported evidence and the issues are promoted to be "solvable" by one simple action - e.g. ban a class of pesticides. But leaders must also try to counter "black swans" by anticipating and being prepared for issues that might suddenly arise. In addition, there is a need to better communicate the agrochemical industry's considerable investment in science and technology resources necessary to address society's human health and environmental concerns. Finally positive responses, rather than negative statements, should be prepared, which can be easily understood and which are not full of impenetrable jargon.

\section{DEVELOPING REGIONS}

Important challenges will arise from the need to provide sufficient food in developing regions where populations are predicted to increase significantly in the coming years. Two presentations were made that reflected on the challenges faced by developing regions. The first by N. A. Shakil on "Views from a Scientifically Emerging Region - India" and the second by J. O. Lalah on "Pesticide Use in Kenya: An Overview of Importation, Regulation and Related Environmental Issues".The population of India is expected to grow from 1.2 billion in 2011 to 1.6 billion in 2050 and agriculture will need to increase its productivity to provide the additional food required. It is estimated that only $20 \%$ of the cultivated area is treated by crop protection measures and there are significant crop losses due 
to pests and diseases. The major class of pesticide used in India is insecticides representing some $60 \%$ of all pesticides used, however, their use is not without problems. These include inappropriate dose rates, increasing pest resistance, poor application technology, destruction of beneficial organisms, illegal residues, counterfeit formulations etc. A further difficulty in ensuring the correct use of pesticides is the fact that there are 428 languages with 1224 dialects. Residues are of particular concern arising from either intentional use of pesticides for protection of crops or the unintentional exposure of crops. The challenges facing crop protection leaders include initiating the training of farmers in the selection of appropriate pesticides and their correct use, the provision of good spray equipment and its use by trained operators and an inventory of obsolete stocks with a plan for their disposal. Currently, India is also carrying out research into various IPM techniques with a view to reducing pesticide use. Research is also being carried out on the potential for safer pesticides based on natural products using plant extracts and plant essential oils.

East Africa, comprising Kenya, Ethiopia, Uganda and Tanzania, is a developing region with an important agricultural sector. In these agriculture-based economies, smallholder farming accounts for about 75 percent of agricultural production and over 75 percent of employment.(12) In Kenya the agricultural sector is the mainstay of the economy, contributing an estimated $27 \%$ of the GDP, and the rapid expansion of agriculture has resulted in a three-fold increase in annual pesticide use. Despite the increased use of pesticides, about $40 \%$ of food production is still lost by insect pests, weeds and plant diseases. Without the proper training of farmers environmental problems can arise with increased use of pesticides. An example is the Lake Naivasha area where there has been a significant increase in irrigated farming, mainly of horticultural crops, especially flowers. The discharge of water from greenhouses and agricultural run-off has contributed to pollution of 
the lake with, for example, some insecticide residues in sediment and water exceeding recommended criteria for the protection of aquatic life and preservation of water quality.(13) A problem in Kenya, as well as in other African countries, is the misuse of pesticides to kill wildlife where there is a conflict between the human population and the wildlife.(14) This includes killing predators of cattle and the protection of crops against birds. Other critical issues in Kenya regarding the use of pesticides are record keeping, education and awareness of the hazards of pesticides, lack of laboratory capacity for analyses relating to contamination, training and a better implementation of existing laws backed up by prosecutions. In addition, it is necessary to strengthen collaboration networks locally and internationally so that technology, scientific knowledge and skills are transferred and kept up to date.

\section{TRAINING}

The future of crop protection relies on universities and technical institutes to carry out research and provide graduates trained in crop protection technologies. The issues besetting academic departments involved in crop protection were discussed by B. Rubin in his presentation "Training Crop Protection Leaders -The Academia Point of View". Despite the recognized need to increase food production the role of the crop protection industry is often underestimated. The interest of our future leaders, namely young scientists and graduate students in crop protection chemistry is declining. The number of universities and colleges that offer crop protection related studies is decreasing markedly. In the agrochemical industry there is a continuous reduction in the number of research based companies due to mergers, with a concomitant increase in the number of generic companies. The impact of the change in the direction of academic research towards more "basic" and more "sustainable" is reflected in the courses syllabi neglecting the "applied" science. Moreover, it results in a recognized shortage of skilled employees and group leaders in both the pesticide research based and 
generic companies. It is proposed that there should be a deeper and significant involvement of the agrochemical companies in academic research and education, actively sponsoring M.Sc. and Ph.D. programs, supporting institutional initiatives to open new pesticide-related study programs and research. Academics must work cooperatively with the agrochemical industry to attract the interest of the younger generation for research that transforms agriculture from low-tech to high-tech. The lack of suitable graduates is already beginning to affect industry.

The continuing need for well trained professionals was the subject discussed by M. Leggett in his presentation "Crop Protection Industry - Workforce Needs". It has been estimated that the global workforce in agriculturally related industries will grow by $6.3 \%$ between 2012 and 2015.(15) Compared to 2012 a larger proportion of the workforce will be from Asia and South America balanced by a smaller proportion in Europe and North America. Taking the US as an example more than 1000 new scientists are expected to be required by 2015, mainly in the areas of plant sciences, plant breeding and genetics and crop protection, other areas requiring new scientists are environmental studies, toxicology, statistics and communications. Nearly half (46\%) of the new hires will need doctoral degrees, $27 \%$ masters degree and 26\% educated to bachelor level. However, it is recognised that companies have difficulty finding quality applicants to fill the roles they have available and will need to retrain some hires in new disciplines. Companies will need to work directly with university departments and support the educational aspirations of motivated students.

\section{REGULATORY AFFAIRS}

In order to have safe and effective crop protection, registration of chemicals by government officials is an absolute necessity. The data needed for registration is immense and complex, 
requiring well trained professional individuals with a broad understanding of both the registration process and the diversity of issues. Therefore, a shortage of such individuals could negatively impact the number of new and innovative crop protection products for submission to the registration process. In her presentation "Training Crop Protection Leaders - Views from Government" J. Van Emon touched on the knowledge required for registration. The process of registering a pesticide is a scientific, legal, and administrative procedure having several components. One needs only to peruse the U.S. Code of Federal Regulations, Chapter 1, Subchapter E-Pesticide Programs(16) to gain an understanding of the complexity of the process and technical skills required. The process, in part, includes examining the ingredients of the pesticide; the particular site or crop where it is to be used; the amount, frequency and timing of its use; and appropriate storage and disposal processes. To help with the registration process, the U.S. EPA Office of Chemical Safety and Pollution Prevention has developed a series of harmonized test guidelines for use in the testing of pesticides and the development of test data for submission to the EPA.(17) The guidelines specify methods that the EPA recommends to generate data that is submitted to the Agency to support registration of a pesticide under the Federal Insecticide, Fungicide and Rodenticide Act (7 U.S. Code 136) and the setting of a tolerance or tolerance exemption for pesticide residues under Section 408 of the Federal Food, Drug and Cosmetic Act (21 U.S. Code 346a). Risk assessments are performed to evaluate the potential harm to humans, wildlife, fish, and plants, particularly endangered species and non-target organisms. Human health risks range from short-term toxicity to long-term effects such as cancer and reproductive system disorders. Environmental stewardship is an integral part of this process and must address contamination of surface water or ground water from leaching, runoff, and spray drift. For crop protection that is based on biotechnology or transgenic plants, substantial equivalence must be proven including compositional analysis, toxicity, allergenicity, and 
unintended effects on non-target organisms. The many facets of the registration process as described above, illustrates that the training of crop protection leaders must include several topical areas. It is not possible to be an expert in all of these areas but researchers who are involved with fulfilling the regulatory requirements for crop protection chemicals should be able to effectively communicate with regulatory officials. This training is also appropriate for individuals who want to become regulatory officials so they will have sufficient knowledge to appreciate the complexities of crop protection research, development and registration.

Following the presentations there were three breakout sessions in order to formulate the challenges and requirements of crop protection leaders in the future. The sessions were based on the needs of industry, lead by B. Saha and C. Corsi, the academic outlook, lead by $\mathbf{J}$. Jenkins and H. Miyagawa and thoughts from government lead by D. Hamilton and C.

\section{Howard.}

\section{KEY ISSUES FOR CROP PROTECTION}

Global Concerns: Today approximately 1 in 8 of the global population is suffering from chronic undernourishment and, unless additional food resources can be found, this figure will increase as the population rises from about 7 billion today to 9 billion in 2050. In addition, climate change and increased biofuel production represent major risks for long-term food security. In order to provide sufficient food and fibre to the increasing population the technologies associated with crop protection have grown ever more sophisticated but, at the same time, societal expectations for stewardship, human safety, environmental protection and agricultural sustainability with respect to use of crop protection chemistry tools are also increasing. This is particularly the case in developed countries where regulations are widely used to safeguard health and the environment through best management practices. In 
developing countries, farm families are first and foremost concerned with producing sufficient food to survive. Regulations safeguarding health and the environment have been employed in these areas by multinational companies and large farms, but this is not necessarily the case on small family farms. Poor economies and the inability to develop and deliver government outreach programs for the safe and efficient use of pesticides put an additional barrier on meeting the same standards that are demanded and enjoyed in developed countries.

New and Evolving Trends: New technologies are constantly being developed that have the potential to change the way that agriculture is carried out. An example of a relatively new technology is nanotechnology. Nano-pesticides or nano plant protection products represent an emerging technological development that, in relation to pesticide use, could offer a range of benefits. A more mature technology, if still not readily accepted in some regions, is the use of GM crops for insect resistance, herbicide resistance and enhanced nutritional value.

It is thought that many new developments will take place in the emerging economies of the world, possibly including the development of a higher percentage of new compounds as pesticides. These may be natural products or derived from natural products modified using the increasing knowledge and innovation in synthetic chemistry. Nano-pesticides and biopesticides(18), botanical and microbially derived chemicals, are playing an increasing role in pest management and this will lead to a rethink on registration strategies. Currently, the emphasis for registration is on "conventional" chemicals but the upcoming bio- and nanopesticides do not necessarily fit with today's registration requirements. It is also important that clear definitions are available for these new types of pesticides. New requirements need to be defined so that their use can be properly regulated and label recommendations enforced. 
The properties of the nano-material that enhance its desired efficacy compared with the normal material may also influence differences in physical and chemical properties that require specification control different from that of the normal material. Biological pesticides, e.g. bacterial larvicides, require different specifications from those of manufactured chemicals. For example, the relevant impurities in biological pesticides are more likely to be microbial or fungal impurities than chemical impurities. Another example is that of accelerated storage stability testing at elevated temperature, which has a theoretical basis and is used for chemicals, but is unlikely to be suitable for some biologicals. Thus some of these pesticides do not fit into current specification guidelines(19) so these are either under revision or will have to be revised.

Harmonised registration requirements, championed by the OECD, are becoming more frequent, particularly in the more developed countries. Harmonisation will allow governments to share work on pesticide registration and re-registration, leading to an overall decrease in the associated costs. Harmonisation of the data and methods used to test and assess pesticide risks is also important as it not only helps governments work together but ensures the quality of the data and the rigour of the assessments. Registration requirements must be based on scientific principles and take into account the difference between risk and hazard. Increasingly there is a tendency to use Quantitative Structure Activity Relationship (QSAR) techniques for toxicology and ecotoxicology predictions and these must be harmonised between countries and introduced through the regulatory system at the same time. Harmonisation of the regulatory procedure would be of particular interest to developing countries but they may not be in a good position to participate due to a lack of infrastructure, including human resource capacity.

With the rise in computing power and the many different ways of collecting information "Big Data" storage and interpretation will be increasingly more relevant ("Big Data" is an all- 
encompassing term for any collection of data sets so large and complex that it becomes difficult to process them using traditional data processing applications). For example, farmers in developed countries or associated with multinational companies are generating significant amounts of data through the use of "smart systems" such as integrated field computers allowing for the use of precision technology in applying chemicals. Although this may enable better record keeping by the farmer, it raises the question as to who else, e.g. agricultural extension personnel affiliated with local, regional or federal governments, should have access to these data. In addition, there are important questions regarding how the data are stored and how to preserve confidentiality and maintain privacy.

As patents expire, generic manufacturers come into the industry with their versions of previously patent protected pesticides. Today, generic pesticides are produced by many sources and sold by companies specialising in supplying these to farmers. The issue for governments is how to regulate these products with regard to their meeting agreed specifications for active ingredient and impurity content. In addition there is the particular problem of how to deal with the intellectual property rights associated with the data, and the costs incurred in obtaining that data. Counterfeit pesticides are a substantial problem and this problem could increase as, for example, small holders increase their use of pesticides.

Communication: With the increase in web based communication tools such as Twitter and Facebook, together with the ease of uploading Blogs, information can now be broadcast without consistent checking of facts. Today, the lines between journalists and bloggers have become seriously blurred when it comes to online content, and journalists are often bloggers compensated on a per "hit" basis. In addition, scientists may seriously overstretch the implications of their research in order to draw attention to it and thereby garner more financial or administrative support. This can lead to articles on pesticides typically having 
exaggerated headlines and often highlighting a mistrust of the chemical industry, based on the result of hyperbolic conclusions that fail to incorporate realistic exposures of the general public. Information and data are available to the general public but may not be in a format that the average non-specialist can fully understand, whilst purely scientific arguments by experts may not be enough to convince the public. Communication to non-specialists should be via methods that are appropriate to the target audience through, for example, journals, trade magazines, newspapers, broadcast media, and social media. Communication must be open, honest and above all timely, in order to build trust between the audience, the wider community, government and industrial corporations. In order that the public has a better understanding of scientific topics more attention should be paid to STEM (science, technology, engineering, and mathematics) education(20) in order to encourage students to take an interest in STEM subjects at an early age. Furthermore, STEM education needs to enhance children's interest by broadening the scope of classes and teaching age appropriate science. Methods for broadening the scope of classes should include offering courses beyond general science (e.g. ecotoxicology for children, atmospheric chemistry, etc.). Teaching age appropriate science would mean that younger children could learn science through directed experiments, which are fun and interesting, while older children/young adults could be tasked with preparing their own experiments, researching the outcome, and developing results. To achieve this academics and school teachers need to continually update their knowledge and use modern techniques of teaching to capture the interest of their students of whatever age.

Stewardship: When pesticide use is not in compliance with the label instructions, there can be a negative effect on human health, the environment and trade. It is important that stewardship schemes are in place to minimise any hazards inherent in their use. Similarly, out-of-specification and counterfeit pesticides can also pose problems even when used according to label instructions. Stewardship, a life cycle approach to product management, is 
the responsible and ethical way to manage crop protection products from their discovery and development, to their use and the final disposal of any waste. The overall aim of the stewardship approach is to maximize the benefits, and minimize any risk, from using crop protection products.(21) Stewardship schemes must reflect the needs of the market into which pesticides are being sold, and ensure that they deal effectively with any specific local issues, e.g. misuse of pesticides for killing wildlife. Proper education and training are necessary if stewardship schemes are going to work effectively and there should be systems in place to measure their effectiveness. To minimise repeating the mistakes of the past, a history of pesticide chemistry and responses to past problems should be included in the education and training courses.

Training Needs: In most cases initial training takes place in universities or other technical institutes. Most academic departments relevant to training in crop protection chemistry have a primary focus in the biological sciences. In the past there were many academic units around the world that focused on "agricultural chemistry", however, these departments have largely all disappeared. Since the late 1980's entomology departments no longer hire faculty to provide training or conduct research in crop protection chemistry and toxicology; a similar situation exists in plant pathology. Agronomy and weed science departments fare better, but are still deficient in meeting the need. In addition, rarely do engineering departments provide training or conduct research in application technology. Academic training in formulation chemistry has always been rare. Undergraduate training rarely covers crop protection chemistry in the context of agronomic practices; rather the focus is on the evaluation of risks to human health or the environment, which is also the focus of most research faculties. Effective training of future crop protection chemistry leaders, who will need to have a good understanding of the many different facets of crop protection, will require a multidisciplinary approach, including basic and applied graduate training in: 
- Chemical, Physical and Biological Sciences

- Agronomy, Agroecology and Soil Science

- Risk assessment (occupational and public health, environment and trade)

- Computer and Systems Science (data handling, modelling)

Training for regulatory work is virtually non-existent except for on the job training. Courses that would prepare individuals to transition from academic to regulatory/industry work are needed. Internships or mentorships would also be valuable to training. In addition, those involved in regulatory work need to know the history of regulatory development and the responses to previous issues of concern. Good communication skills will be an absolute necessity for future leaders and increased training is needed in this area. Those unfamiliar with agriculture practices, including the public, policy makers, and members of the scientific community, generally lack an adequate understanding of the regulatory oversight of agricultural technologies. Future leaders must be able to effectively communicate risk assessment methodologies that inform the risk management process which is designed to meet strict human and environmental health protection goals.

\section{PROPOSALS FOR CHANGE}

The key issue for leaders in crop protection in the 21 st Century is the need to have appropriate training and this should be a continuing process throughout the careers of those involved in crop protection. Academia universally claims to be sensitive to the needs of employers and many profess to strategic planning that attempts to keep pace with changing workforce requirements, and to forecast future needs. However, at research universities the reality is often that faculty members are hired based primarily on current and anticipated funding sources and their ability to secure external funding. It has been a continuing trend over the years that government funding of crop protection chemistry is generally meagre and 
462

463

464

465

466

467

468

469

470

471

472

473

474

475

476

477

wholly inadequate.(22) Industry funding is also not common for research that must meet stringent regulatory requirements, since laboratories must be GLP compliant and the results must remain confidential, thus precluding timely publication in scientific journals. In addition, many faculties conducting relevant basic or applied research, and thereby training graduate students with expertise useful to industry, are reluctant to accept industry funding due to the perception of industry bias.

The key factors required to ensure the development of crop protection leaders in the 21 st Century are:

- Outreach programs in crop protection for schools, colleges and universities, possibly organised via industry associations - to give students an understanding of crop protection issues from an early stage.

- Outreach to university students to consider a career in crop protection chemistry

- Outreach to university administrators as to the need for crop protection chemistry research - dealing with climate change, food security, invasive species, etc.

- Ensure that the basic science behind crop protection is adequately taught

- Attract the best students to study crop protection by:

- Joint industry and academia programs supported by scholarships with involvement of scientists from industry in teaching and supervision of research students

- Direct funding from industry for research projects suitable for M.Sc. and Ph.D. theses

- Less restrictive publication policies from industry 
- Ensure long term funding for research faculties to train graduate students that may become future crop protection chemistry leaders, this will require a significant change in government funding policy, which over the last 2 decades has largely moved away from funding "controversial" crop protection technologies

- Create a new curriculum at universities - "Food Security and Crop Protection Science" that will cover major aspects of crop production

- In the longer term provide an academic environment that allows future leaders to excel at teaching, research, and outreach

- Teach communication skills as an integral part of the training of crop protection leaders - including more evidenced- based communication in both scientific journals and more general publications that highlight the global benefits of crop protection products

- Industry to invest more in public relations and stewardship to counteract the negative image of certain aspects of crop protection, including a better understanding of society's concern and the need to respond in a reasoned manner when misinformation arises

There is a need for increasing productivity in agriculture as the global population increases but the land mass available to agriculture either remains the same or is shrinking due, for example, to urbanisation. At the same time the percentage of the population in developed countries actively working in agriculture is falling and this trend is beginning to occur in developing regions as the countries become less poor. As the general population becomes more remote from the issues involved in maintaining a secure food supply the need for crop 
506

507

508

509

510

511

512

513

514

515

516

517

518

519

520

521

522

523

524

525

526

527

protection measures is less appreciated by the public. At the same time well publicised real or perceived problems with crop protection methods lead to a negative view of their usefulness.

The prevailing view of the participants was that in order to prepare leaders for crop protection in the future there should be dedicated departments in universities, teaching and researching crop protection systems, thus reversing the disappearance of units focussed on "agricultural chemistry" which existed in the past. These departments should concentrate on the fundamentals of chemical, physical and biological sciences, together with modules on risk assessment, formulation chemistry, new technologies in crop protection, computer modelling, communication techniques and regulatory issues. The key for training well-rounded crop protection leaders is to develop faculties in universities that enjoy good administrative support, that have appropriate and adequate funding and that develop a reputation as a first class unit that can attract the best students.

As an IUPAC sponsored symposia the recommendations will be passed to the members of the IUPAC Division of Chemistry and the Environment and, in particular, the Advisory Committee on Crop Protection Chemistry with a view to initiating a follow-up program. Members of these bodies are representatives of academia, industry and government and are well placed to instigate a suitable project to see how the recommendations can be implemented.

Acknowledgement: Appreciation for financial support is expressed to the American Chemical Society (Division of Agrochemicals) and the International Union of Pure \& Applied Chemistry (Division of Chemistry and the Environment) 
(1) Godfray, H.C.J., Beddington, J.R., Crute, I.R., Haddad, L., Lawrence, D., Mir, J.F., Pretty, J., Robinson, S., Thomas, SM. and Toulmin, C., Food Security: The Challenge of Feeding 9 Billion People, Science 2010, 327, 812-818

( 2) Alexandratos, N and Bruinsma, J., World Agriculture Towards 2030/2050: The 2012 Revision, ESA Working Paper No. 12-03, June 20, Rome, FAO http://www.fao.org/docrep/016/ap106e/ap106e.pdf (accessed 16 March 2015)

(3) What is Sustainable Agriculture ? Agricultural Sustainability Institute, UC Davis, California, USA http://www.sarep.ucdavis.edu/about-sarep/def (accessed 12 December 2014)

(4) Investing in Woman Smallholder Farmers, An Action Aid International Briefing, June 2011 http://www.actionaid.org/sites/files/actionaid/policy briefinginvesting in women smallholder farmers.pdf (accessed 12 December 2014)

(5) The State of Food and Agriculture 2010-11: Closing the Gender Gap for Development, FAO, Rome, 2011 http://www.fao.org/docrep/013/i2050e/i2050e.pdf (accessed 12 December 2014)

(6) Fields of Automation; Robotics: A new generation of agricultural equipment promises to take more of the toil out of farming by automating the business of growing fruit, The Economist, December 10, 2009 http://www.economist.com/node/15048711 (accessed 12 December 2014) 
(7) IBM, Big Data at the Speed of Business http://www-

01.ibm.com/software/data/bigdata/what-is-big-data.html (accessed 12 December 2014)

(8) US EPA, Übertool: Web Applications for Ecological Risk Assessment

http://www.ubertool.org/ (accessed 12 December 2014)

(9) Gogos, A., Knauer, K. and Bucheli, T.D. Nanomaterials in Plant Protection and Fertilization: Current State, Foreseen Applications, and Research Priorities. J. Agric. Food Chem. 2012, 60, 9781-9792.

(10) Kookana, R.S., Boxall, A.B.A., Reeves, P.T., Ashayer, R., Beulke, S., Chaudry, Q., Cornelis, G., Fernandes, T.F., Gan, J., Kah, M., Lynch, I., Ranville, J., Sinclair, C., Spurgeon, D., Tiede, K. and Van den Brink, P.J. Nanopesticides: Guiding principles for regulatory evaluation of environmental risks. J. Agric. Food Chem. 2014, 62, 4227-4240.

(11) Wauchope, R.D. On the Regulation of Frightening Technologies: Some Lessons from Pesticides. Environ. Impact Assessment Rev. 2000, 20, 505-512

(12) Salami, A., Kamara, A.B. and Brixiova, Z. Smallholder Agriculture in East Africa: Trends, Constraints and Opportunities, African development Bank Group, Working Paper Series No. 105

http://www.afdb.org/fileadmin/uploads/afdb/Documents/Publications/WORKING\%20105\%2 0\%20PDF\%20d.pdf (accessed 12 December 2014) 
(13) Otieno, P.O., Owuor, P.O. Lalah, J.O. Pfister, G. and Schramm, K-W. Impacts of Climate-Induced Changes on the Distribution of Pesticide Residues in Water and Sediment of Lake Naivasha, Kenya, Environ. Monit. Assess. 2012, 185, 2723-2733

(14) Ogada, D.L. The Power of Poison: Pesticide Poisoning of Africa’s Wildlife Ann. N.Y. Acad. Sci. 2014, 1-20

(15) Coalition for a Sustainable Agricultural Workforce, 2013 Agricultural Science Workforce Censusmhttp://www.sustainable-agworkforce.org/sites/g/files/g157851/f/attachments/CSAW2013Census.pdf (accessed 12 December 2014)

(16) Code of Federal Regulations Title 40, Chapter 1, Subchapter E, Pesticide Programs http://www.gpo.gov/fdsys/pkg/CFR-2011-title40-vol24/pdf/CFR-2011-title40-vol24-chapIsubchapE.pdf (accessed 10 March 2015)

(17) EPA Harmonized Test Guidelines, January 28, 2015

http://www.epa.gov/ocspp/pubs/frs/home/guidelin.htm (accessed 10 March 2015)

(18) Seiber, J.N., Coats, J., Duke, S.O. and Gross, A.D. (2014) Biopesticides: State of the Art and Future Opportunities. J. Agric. Food Chem. 2014, 62, 11613-11619

(19) WHO and FAO. 2010. Manual on Development and Use of FAO and WHO Specifications for Pesticides. Second revision of the First Edition. World Health Organization and Food and Agriculture Organization of the United Nations, Rome, 2010 
(20) US Department of Education, Science, Technology, Engineering and Math: Education for Global Leadership http://www.ed.gov/stem (accessed 12 December 2014)

(21) CropLife International, Stewardship https://croplife.org/crop-protection/stewardship/ (accessed 12 December 2014)

(22) Wauchope, R.D., Special Panel Discussion Session at the 9th International Congress of Pesticide Chemistry: The Role of Publicly Funded Research in the Risk Assessment and Registration of Pesticides. Chem. Int. 1999, 21, 23-24 
For Table of Contents Only

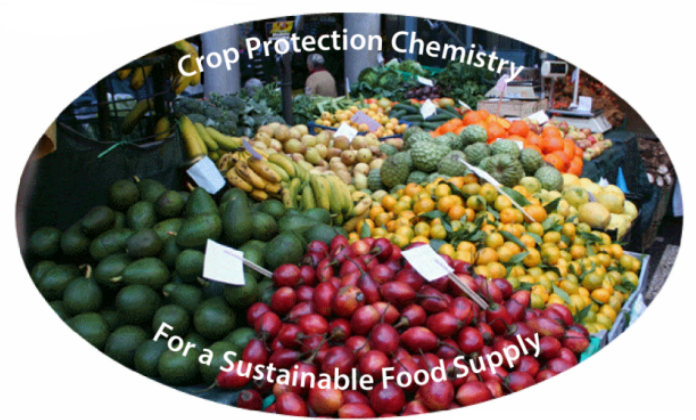

